\title{
Hubungan Customer Relationship Management dengan Loyalitas Nasabah (Studi Kasus: PT Bank XYZ Cabang Bogor)
}

\author{
The Relationship Between Customer Relationship Management and Customer Loyalty \\ (Case Study: PT Bank XYZ Branch Bogor)
}

\author{
Reni Sanjaya $^{1 *}$, Ujang Sumarwan ${ }^{2 \#}$ dan Kirbrandoko ${ }^{3 \#}$ \\ ${ }^{1}$ Magister Manajemen dan Bisnis, Sekolah Pascasarjana Institut Pertanian Bogor \\ ${ }^{2}$ Dosen Program dan Pascasarjana Magister Manajemen Bisnis Institut Pertanian Bogor \\ Jl Raya Pajajaran Bogor; e-mail: sumarwan@mb.ipb.ac.id \\ ${ }^{3}$ Dosen Program dan Pascasarjana Magister Manajemen Bisnis Institut Pertanian Bogor \\ Jl Raya Pajajaran Bogor; e-mail: koko_kir@yahoo.com
}

\begin{abstract}
ABSTRAK
Kajian ini bertujuan untuk menganalisis hubungan antara customer relationship management (CRM) yang diukur melalui persepsi nasabah dengan tingkat loyalitas nasabah. Model pada kajian ini menggunakan recency, frequency dan monetary (RFM) untuk mengukur loyalitas dan CRM melalui people, process dan technology. Analisis yang digunakan meliputi analisis deksriptif, korespondensi, khi-kuadrat dan regresi. Data yang digunakan berupa data primer dan sekunder. Pengumpulan data primer dilakukan dengan wawancara terstruktur bedasarkan skala likert. Prosedur pengambilan populasi memakai purposive sampling, yaitu nasabah tabungan SiAga kerjasama dengan nominal Rp25 juta s/d < Rp175 juta sebanyak 100 orang dengan metode sensus. Analisis CRM dilakukan atas peubah people dengan indikator antusiasme, keramahan dan kemampuan; peubah process diukur dengan indikator identifikasi profil, komunikasi, pemberian souvenir, penanganan keluhan pelanggan dan customized; peubah teknologi dengan indikator database nasabah dan media komunikasi. Berdasarkan segmentasi RFM dihasilkan lima segmen, yaitu segmen platinum, segmen emas, segmen silver, segmen blue dan segmen black. Hasil penelitian memetakan bahwa mayoritas nasabah tabungan SiAga kerjasama XYZ terdapat pada segmen Silver (57\%) dengan tingkat recency tinggi; sementara pada aspek frequency dan monetary cenderung rendah, sedangkan untuk nasabah dengan tingkat RFM tinggi (segmen platinum) hanya $12 \%$. Persepsi nasabah mengenai CRM yang dilakukan Bank XYZ bedasarkan people, process dan technology menghasilkan nilai persepsi paling tinggi yaitu pada kesesuaian database nasabah (aspek teknologi). Namun, nasabah belum memanfaatkan fasilitas penggunaan teknologi dan belum merasakan mengenai kemudahan transaksi dengan teknologi. Berdasarkan analisis regresi antara CRM dan loyalitas, aspek proses bisnis paling memengaruhi frekuensi dan monetary, kemudian diikuti dengan aspek teknologi yang memengaruhi monetary. Untuk aspek people tidak memengaruhi tinggi atau rendahnya nilai RFM. Semakin loyal nasabah, maka semakin tinggi persepsi penilaian mengenai Bank $\mathrm{XYZ}$ yang dilihat dari aspek people, process dan technology.
\end{abstract}

Kata kunci: customer relationship management, loyalitas nasabah, model RFM

\section{ABSTRACT}

Purpose of this study is to analyze the relationship between customer relationship management (CRM) which is measured through customer perception with the level of customer loyalty. The models used in this study are recency, frequency and monetary (RFM) that measures loyalty and CRM through people, process and technology. The analysis used is descriptive analysis, correspondence analysis, chisquare analysis and regression analysis. The data used are primary and secondary data. Primary data were collected with a structured interview based on the Likert scale. The population in this study is using

\footnotetext{
*) Korespondensi:

Jl Ir H. Djuanda No. 36 Bogor 16122, Telp. 02518362020, Hp. 081808973555, email: sanjaya.reni@gmail.com, fax. 02518361044
} 
purposive sampling, the customers of tabungan SiAga with nominal savings Rp25 million up to $<175$ million as many as 100 people are taken by the census method. The analyses of CRM the people variable with the indicators consist of enthusiasm, friendliness and ability; the process variables measured by indicators of profile identification, communication, souvenirs, and handling customer complaints and customized; the technology variable which indicators consist of customer database and communication media. While RFM analysis is measured by variables Recency, Frequency and Monetary. Based on segmentation RFM there are five segments; the segments are platinum segment, gold segment, silver segment, blue segment and black segment. The study states that the majority of tabungan SiAga XYZ costumers are in the silver segment (57 percent) with a high degree of recency; while the frequency and monetary aspects tends to be low, while for customers with a level of RFM that are high (platinum segment) about 12 percent. Meanwhile perception of the customers about CRM by Bank XYZ based on people, process and technology produce that the highest perception is in conformity of the customer database (technological aspects). However, customers have not been using the technological facilities and yet feel about the ease of transaction with technology. Based on regression analysis between CRM and loyalty, aspect of the business processes most affect the frequency and monetary, and then followed with the technological aspects that affect monetary. For people aspect does not affect the high or low value of RFM. The more loyal customer, the higher perception about the Bank XYZ is seen from the aspect of people, process and technology.

Key words: customer relationship management, customer loyalty, RFM model

\section{PENDAHULUAN}

Perkembangan pemasaran perbankan semakin meningkat dan bersaing ketat. Pertumbuhan indutri perbankan telah bertransformasi dari hanya sekedar menawarkan produk, jasa dan layanan menjadi relationship marketing yang berpusat pada pelanggan (customer centric). Menurut Gitomer dalam Kotler dan Keller (2007), tantangan saat ini bukanlah menghasilkan pelanggan yang puas, melainkan pelanggan yang senang dan setia. Membangun relasi yang baik dengan pelanggan akan jauh lebih bermakna daripada hanya sekedar menjual produk atau jasa bermutu tinggi. Hal tersebut dinyatakan pada penelitian Hussain et al (2009), Bank perlu mengetahui kebutuhan dan permintaan dari setiap target nasabah dan membuat strategi agar lebih efektif dan efisien. Oleh karena itu, dibutuhkan suatu cara tepat, agar perusahaan dapat mengetahui pelanggannya menurut kebutuhan dan keinginan pelanggan. Menurut Andreani et al (2012), customer relationship management (CRM) merupakan salah satu strategi untuk retain customer, yang diperoleh dari menjaga hubungan dengan pelanggan dengan harapan bahwa konsumen akan loyal kepada perusahaan. Hal tersebut diperkuat dengan penelitian yang dilakukan oleh Imasari dan Nursalin (2011), Nadlifatin et al (2009), serta Munandar (2006) yang menghasilkan bahwa CRM berpengaruh terhadap loyalitas pelanggan.
Loyalitas itu sendiri berpengaruh terhadap tingkat profitabilitas terhadap perusahaan, seperti penelitian yang dilakukan oleh Prihartono, et al (2012) mengemukakan bahwa loyalitas sangat berpengaruh nyata terhadap tingkat profitabilitas perusahaan dan pendapatan bersama.

Bank XYZ Cabang Bogor merupakan salah satu Cabang yang memiliki pertumbuhan tabungan yang tinggi (Bukopin, 2012), terutama pada produk tabungan SiAga kerjasama dari segi customer based menempati posisi terbanyak dibandingkan dengan produk tabungan lain. Tabungan siaga kerjasama itu sendiri adalah tabungan khusus nasabah yang melakukan penggajian (payroll) melalui Bank XYZ. Walaupun XYZ Cabang Bogor terbanyak menjual tabungan SiAga kerjasama, namun banyak rekening SiAga kerjasama yang dorman atau pasif, dengan kata lain banyak nasabah tidak aktif. Hal tersebut bisa diakibatkan karena Bank XYZ belum fokus terhadap target potensial. Salah satu cara yang dapat digunakan untuk mengelola hubungan terhadap pelanggan adalah dengan memahami, serta memberikan perlakuan yang berbeda-beda sesuai dengan karakteristik pelanggan pada setiap segmen.

Miglautsch (2000) menyatakan bahwa salah satu teknik segmentasi adalah Recency, Frequency, and Monetary (RFM) dalam mengukur tingkat keloyalan nasabah yang dilihat dari pola perilaku transaksi masa lalu. Penelitian terdahulu seperti Ariana dan Bagus (2011), Bacila et al (2012), 
Winner (2001) serta Aviliani, et al (2011), Irmariani (2013) meneliti mengenai metode sistem keputusan yang menggunakan data mining pada perusahaan. Model yang digunakan adalah pola segmentasi pelanggan dengan model RFM.

Tabel 1. Customer based tabungan XYZ tahun 2013

\begin{tabular}{lc}
\hline Jenis tabungan & Jumlah account \\
\hline Tabungan Rencana & 714 \\
Tabungan Siaga kerjasama & 8313 \\
Tabungan Siaga Bisnis & 286 \\
Tabungan Haji & 144 \\
Tabungan Premium & 47 \\
Tabungan Ku & 6737 \\
\hline
\end{tabular}

Sumber: BIS Bukopin (2014)

Selain itu, kajian ini membahas bagaimana persepsi nasabah terhadap Bank XYZ apakah berkorelasi positif dengan transaksi yang dilakukan nasabah atau sebaliknya. Iriana et al (2006) meneliti CRM untuk mengukur kinerja internal (orang/karyawan dan manajemen) sebagai pelaksana CRM. Pada penelitian Kanaidi dan Kurniawan (2012), Siahaan (2008) dan Vazifehdust et al (2012) menjelaskan bahwa pelaksanaan CRM perlu memperhatikan aspek people yang terlibat dengan kemampuan dalam mengadopsi perubahan, aspek process (proses bisnis) menilai seberapa baik proses bisnis yang sudah dimiliki dilihat dari sudut pandang

Tabel 2. Definisi operasional peubah RFM

\begin{tabular}{|c|c|c|c|c|}
\hline $\begin{array}{c}\text { Peubah/ } \\
\text { Sub peubah }\end{array}$ & Definisi Peubah/Sub peubah & Indikator & Ukuran & Skala \\
\hline Recency & $\begin{array}{l}\text { Dimensi untuk mengetahui waktu nasabah } \\
\text { terakhir kali melakukan transaksi (Womack } \\
\text { dan Butler 2004). }\end{array}$ & $\begin{array}{l}\text { Semakin sedikit selisih } \\
\text { antar transaksi terakhir } \\
\text { dengan waktu } \\
\text { sekarang maka skor } \\
\text { semakin tinggi. }\end{array}$ & $\begin{array}{l}\text { Waktu transaksi } \\
\text { terakhir per nasa- } \\
\text { bah tahun } 2013\end{array}$ & Rasio \\
\hline Frequency & $\begin{array}{l}\text { Dimensi untuk mengetahui seberapa sering } \\
\text { pelanggan/nasabah melakukan transaksi } \\
\text { pada priode waktu tertentu. Pada penelitian } \\
\text { ini periode waktu dalam } 12 \text { bulan terakhir } \\
\text { (Womack dan Butler 2004). Transaksi disini } \\
\text { merupakan seluruh transaksi yang dilaku- } \\
\text { kan oleh nasabah baik yang menghasilkan } \\
\text { laba/fee base maupun tidak menghasilkan } \\
\text { laba. }\end{array}$ & $\begin{array}{l}\text { Frekuensi (jumlah) } \\
\text { transaksi, dimana } \\
\text { semakin tinggi } \\
\text { frekuensi transaksi, } \\
\text { maka skor frekuensi } \\
\text { semakin tinggi. }\end{array}$ & $\begin{array}{l}\text { Frekuensi transaksi } \\
\text { per nasabah pada } \\
\text { tahun } 2013\end{array}$ & Rasio \\
\hline Monetary & $\begin{array}{l}\text { Ukuran satuan rupiah yang dikeluarkan } \\
\text { nasabah dalam setiap transaksi yang meng- } \\
\text { hasilkan fee base dan profit pada periode } 12 \\
\text { bulan terakhir, (Womack dan Butler, 2004). } \\
\text { Transaksi yang menhasilkan laba seperti } \\
\text { transfer ke Bank lain, pembayaran listrik, } \\
\text { biaya administrasi dan lain-lain. }\end{array}$ & $\begin{array}{l}\text { Semakin besar nasabah } \\
\text { melakukan transaksi } \\
\text { yang menghasilkan fee } \\
\text { base, maka semakin } \\
\text { tinggi nilai monetary. }\end{array}$ & $\begin{array}{l}\text { Pendapatan yang } \\
\text { diterima oleh Bank } \\
\text { dari tiap nasabah } \\
\text { pada periode } \\
\text { tahun } 2013\end{array}$ & Rasio \\
\hline
\end{tabular}

keinginan konsumen dan kebutuhan perusahaan, serta aspek teknologi, karena pemilihan teknologi yang tepat dapat mendukung pemenuhan kebutuhan pelanggan dengan cepat. Mishra (2009) mengkaji implementasi CRM dalam mengukur kinerja manjemen dengan menggunakan teknologi informasi (TI).

Oleh karena itu, pada kajian ini akan dikaji dari sisi persepsi nasabah terhadap CRM yang telah diterapkan oleh pihak Bank XYZ melalui aspek people, process dan technology (Anton dalam Goldenbery, 2002 dan Kalakota dan Robinson, 2001). Adapun tujuan dari kajian ini yaitu: (1) memetakan segmentasi nasabah tabungan SiAga kerjasama XYZ berdasarkan tingkat loyalitas yang diukur dengan RFM, (2) menganalisis relationship melalui persepsi nasabah terhadap CRM dan (3) menganalisis hubungan antara CRM dan loyalitas.

\section{METODE PENELITIAN}

Penelitian kajian ini dilakukan di Bank XYZ Cabang Bogor pada bulan Agustus 2014 sampai Maret 2015. Penelitian menggunakan metode deskriptif dalam bentuk studi kasus. Jenis data berupa data primer dan sekunder. Data primer dan sekunder pada penelitian ini diperoleh dengan cara: (1) wawancara langsung meng- 
Tabel 3. Definisi operasional peubah CRM

\begin{tabular}{|c|c|c|c|c|}
\hline $\begin{array}{c}\text { Peubah/ } \\
\text { Subpeubah }\end{array}$ & $\begin{array}{c}\text { Definisi Peubah/Sub } \\
\text { peubah }\end{array}$ & Indikator & Ukuran & Skala \\
\hline $\begin{array}{l}\text { People } \\
\text { (Kalakota } \\
2001 \text { ) }\end{array}$ & $\begin{array}{l}\text { Orang/pihak bank yaitu } \\
\text { marketing atau customer } \\
\text { service dalam melayani } \\
\text { dan berhubungan dengan } \\
\text { pelanggan }\end{array}$ & $\begin{array}{l}\text { Antusiasme, } \\
\text { Keramahan dan } \\
\text { Kemampuan }\end{array}$ & $\begin{array}{l}\text { Tingkat antusiasme, Tingkat } \\
\text { keramahan, Tingkat } \\
\text { kemampuan }\end{array}$ & Interval \\
\hline $\begin{array}{l}\text { Process } \\
\text { (Kalakota } \\
2001)\end{array}$ & $\begin{array}{l}\text { Sistem dan prosedur yang } \\
\text { membantu marketing atau } \\
\text { customer service untuk lebih } \\
\text { mengenal dan menjalin } \\
\text { hubungan dekat dengan } \\
\text { nasabah }\end{array}$ & $\begin{array}{l}\text { Identifikasi profil } \\
\text { nasabah, Komunikasi, } \\
\text { Pemberian souvenir } \\
\text { pada pelanggan, } \\
\text { Penanganan keluhan } \\
\text { pelanggan, } \\
\text { Customized }\end{array}$ & $\begin{array}{l}\text { Tingkat kelengkapan } \\
\text { informasi profil nasabah, } \\
\text { Tingkat frekuensi komunikasi } \\
\text { dengan nasabah, } \\
\text { Tingkat frekuensi pemberian } \\
\text { souvenir pada nasabah, } \\
\text { Tingkat kecepatan } \\
\text { penanganan keluhan } \\
\text { pelanggan, } \\
\text { Tingkat pemenuhan keinginan } \\
\text { pelanggan. }\end{array}$ & Interval \\
\hline $\begin{array}{l}\text { Technology } \\
\text { (Kalakota } \\
\text { 2001) }\end{array}$ & $\begin{array}{l}\text { Penggunaan informasi } \\
\text { teknologi dalam } \\
\text { membantu mempercepat } \\
\text { dan mengoptimalkan } \\
\text { aktivitas dalam melakukan } \\
\text { proses bisnis }\end{array}$ & $\begin{array}{l}\text { Database pelanggan, } \\
\text { Media komunikasi }\end{array}$ & $\begin{array}{l}\text { Tingkat kesesuaian, } \\
\text { Tingkat kelengkapan Media } \\
\text { komunikasi }\end{array}$ & Interval \\
\hline
\end{tabular}

gunakan skala likert (summated rating scale). Skala ini banyak digunakan karena memberi peluang kepada responden mengekspresikan perasaannya dalam bentuk persetujuan terhadap suatu pernyataan (Sumarwan, 2011b); (2) Pengumpulan data dan informasi jenis transaksi diperoleh dari data transaksi nasabah dan data profil nasabah Tabungan SiAga Kerjasama XYZ Bogor.

Populasi dalam menganalisis RFM dan persepsi nasabah pada kajian ini memakai purposive sampling, dimana contoh data telah ditentukan yaitu nasabah dengan nominal Rp 25 juta s.d $<175$ juta sebanyak 100 orang. Terdiri dari $55 \%$ termasuk nasabah dorman atau pasif dan sebanyak $45 \%$ merupakan nasabah aktif. Rekening dikategorikan dorman atau pasif jika tidak melakukan transaksi dalam 3 (tiga) bulan terakhir.

Teknik pengolahan data pada kajian ini terbagi menjadi tahap wawancara, input, tahap analisis dan tahap hasil. Tahap input dilakukan dengan analisis dekriptif, analisis RFM scoring dengan assigned point, analisis faktor, analisis korespondensi dan analisis regresi.

Analisis RFM scoring, pertama-tama melakukan penyortiran transaksi yang dilakukan oleh nasabah. Recency, database nasabah disortir dari transaksi yang paling baru ke transasksi yang paling lama. Frequency, database nasabah disortir dari frekuensi transaksi yang paling banyak ke frekuensi transaksi yang terdikit. Monetary, nilai diperoleh dari perhitungan biaya yang memberikan keuntungan bagi Bank baik melalui teller man anjungan tunai mandiri (ATM).

Tahap selanjutnya adalah memberikan assigned point untuk matrik $\mathrm{R}, \mathrm{F}$ dan $\mathrm{M}$ yang dapat dilihat pada Tabel 4, 5 dan 6 .

Tabel 4. Assigned point untuk recency

\begin{tabular}{clcc}
\hline $\begin{array}{c}\text { Assigned } \\
\text { Point }\end{array}$ & $\begin{array}{c}\text { Periode } \\
\text { Transaksi }\end{array}$ & $\begin{array}{c}\text { Jumlah } \\
\text { Nasabah } \\
\text { (orang) }\end{array}$ & $\begin{array}{c}\text { Persentase } \\
\text { (\%) }\end{array}$ \\
\hline 20 & $\begin{array}{l}\text { November- } \\
\text { Desember }\end{array}$ & 91 & 91 \\
10 & $\begin{array}{l}\text { September- } \\
\text { Oktober }\end{array}$ & 1 & 1 \\
5 & Juli-Agustus & 1 & 1 \\
3 & April-Juni & 5 & 5 \\
1 & Januari-Maret & 2 & 2 \\
\hline
\end{tabular}

Tabel 5. Assigned point untuk frequency

\begin{tabular}{cccc}
\hline $\begin{array}{c}\text { Assigned } \\
\text { Point }\end{array}$ & $\begin{array}{c}\text { Frekuensi } \\
\text { Transaksi }\end{array}$ & $\begin{array}{c}\text { Jumlah } \\
\text { Nasabah } \\
\text { (orang) }\end{array}$ & $\begin{array}{c}\text { Persentase } \\
(\%)\end{array}$ \\
\hline 5 & $>20$ & 15 & 15 \\
4 & $16-20$ & 14 & 14 \\
3 & $11-15$ & 16 & 16 \\
2 & $6-10$ & 22 & 22 \\
1 & $1-5$ & 33 & 33
\end{tabular}


Tabel 6. Assigned point untuk monetary

\begin{tabular}{clcc}
\hline $\begin{array}{c}\text { Assigned } \\
\text { Point }\end{array}$ & $\begin{array}{c}\text { Monetary } \\
\text { Transaksi } \\
(\mathrm{Rp})\end{array}$ & $\begin{array}{c}\text { Jumlah } \\
\text { Nasabah } \\
\text { (orang) }\end{array}$ & $\begin{array}{c}\text { Persentase } \\
(\%)\end{array}$ \\
\hline 5 & $>30.001$ & 18 & 18 \\
4 & $22.501-30.000$ & 12 & 12 \\
3 & $15.00-22.500$ & 10 & 10 \\
2 & $7.501-15.000$ & 20 & 20 \\
1 & $1-7.500$ & 40 & 40 \\
\hline
\end{tabular}

Setelah skoring tahapan selanjutnya menggunakan analisis faktor (Baroroh, 2013), yaitu menguji faktor-faktor yang akan dianalsis menggunakan uji Bartlett Test of Spericity dan Measure of Sampling Adequancy (MSA). Jika nilai Barlett hitung > Bartlett tabel atau Sign < Alpha $5 \%$, maka menunjukkan bahwa terjadi korelasi nyata diantara peubah yang dianalisis dan proses dapat dilanjutkan. Measure of Sampling Adequancy (MSA) dalam Statistical Package for Social Science (SPSS) menggunakan indeks Kaiser Meyer Olkin, sehingga sering disebut Kaiser Meyer Olkin Measure of Sampling Adequancy (KMO MSA). Nilai KMO MSA 0,5-1,0 menunjukkan bahwa proses analisis faktor yang dilakukan sudah tepat dan dapat dilanjutkan. Setelah itu proses pemisahan peubah-peubah yang memenuhi korelasi dari nilai MSA sebelumnya menjadi suatu kelompok atau grup. Pada kajian ini menggunakan Principal Component Analysis (PCA).

\section{HASIL DAN PEMBAHASAN}

Kajian ini, melakukan analisa terhadap profil nasabah meliputi jenis kelamin, usia, tingkat pendidikan, tingkat pekerjaan dan tingkat pendapatan. Profil nasabah berdasarkan jenis kelamin didominasi oleh nasabah dengan jenis kelamin laki-laki (68\%) dibandingkan dengan perempuan (32\%). Persentase terbesar profil nasabah pada usia 41-50 tahun (44\%), kemudian diikuti dengan nasabah berusia $31-40$ tahun (23\%), 51-60 tahun $(20 \%)$, di atas 60 tahun $(10 \%)$ dan terkecil, yaitu di bawah 30 tahun (5\%). Profil nasabah berdasarkan tingkat pendidikan, persentase terbesar tingkat pendidikan sarjana (41\%), kemudian diikuti dengan nasabah tingkat pendidikan pascasarjana (25\%), SMA (23\%), diploma $(8 \%)$, doktor $(2 \%)$ dan terendah SMP (1\%).

Persentase terbesar profil nasabah berada di wilayah Kabupaten Bogor (31\%), kemudian diikuti dengan nasabah di wilayah Jadetabek
(27\%), Tanah Sareal (13\%), Bogor Barat (9\%), Bogor Utara $(8 \%)$, Bogor Timur $(6 \%)$, Bogor Tengah (4\%) dan paling sedikit nasabah berada di Bogor Selatan (2\%). Persentase terbesar profil nasabah bekerja sebagai pegawai swasta $(66 \%)$, kemudian diikuti dengan nasabah yang bekerja sebagai profesional seperti dokter, pengacara $(28 \%)$, paling sedikit dengan pekerjaan pegawai negeri, pegawai BUMN, dan pensiunan masingmasing memiliki jumlah persentase $2 \%$.

Profil penempatan dana nasabah XYZ Bogor menunjukkan bahwa nasabah dengan penempatan dana Rp25 juta-Rp50 juta mendominasi $(53 \%)$, diikuti dengan nasabah penempatan dana Rp51 juta-Rp100 juta (31\%) dan nasabah urutan terakhir yaitu nasabah dengan nominal penempatan dana Rp100 juta-Rp175 juta (16\%).

Hasil penelitian menunjukkan bahwa penarikan tunai melalui ATM XYZ (28,09\%) dan penarikan tunai di ATM Bank lain (25,26\%) merupakan dua transaksi yang paling sering dilakukan oleh nasabah tabungan SiAga kerjasama XYZ Cabang Bogor pada tahun 2013. Transaksi tersebut merupakan transaksi yang tidak mengeluarkan dana, walaupun penarikan di ATM bank lain namun terdapat program gratis tarik tunai di ATM manapun, apabila saldo setelah penarikan minimal $\mathrm{Rp} 2$ juta. Fitur transaksi justru memberikan keuntungan bagi Bank XYZ seperti RTGS (0,19\%), info saldo di ATM Bank lain $(3,11 \%)$, transfer ke Bank lain melalui ATM (6,12\%) dan pembayaran tagihan kartu kredit. Adapun aktivitas nasabah rekening SiAga kerjasama dapat terlihat pada Tabel 7.

\section{Analisis Segmentasi RFM}

Salah satu tujuan kajian ini menentukan segmentasi nasabah bedasarkan peubah RFM. Seluruh nasabah yang terdaftar pada data transaksi dianalisis berdasarkan tanggal terakhir melakukan transaksi, frekuensi transaksi rataan per bulan dan besarnya dana transaksi yang dikeluarkan nasabah untuk Bank XYZ rataan per bulan.

Kesimpulan tentang layak tidaknya analisis faktor yang dilakukan menggunakan uji KaiserMeyer-Olkin (KMO) measure of adequacy dan Barlett Test of Spericity (Baroroh, 2013). Pada Tabel 8 dapat dilihat bahwa nilai KMO 0,501, maka faktor ini layak dilakukan. 
Tabel 7. Frekuensi transaksi nasabah Tabungan SiAga Kerjasama pada tahun 2013.

\begin{tabular}{|c|c|}
\hline Jenis transaksi & $\begin{array}{c}\text { Persentase } \\
(\%)\end{array}$ \\
\hline Setoran tunai & 1,55 \\
\hline Pemindahbukuan antar Bukopin & 2,04 \\
\hline Penarikan tunai di teller & 2,43 \\
\hline Penarikan tunai di ATM Bukopin & 28,09 \\
\hline $\begin{array}{l}\text { Transfer ke Bank lain melalui ATM dan } e^{-} \\
\text {banking. }\end{array}$ & 6,12 \\
\hline Penarikan tunai di ATM lain & 25,56 \\
\hline Real Time Gross Settlement (RTGS) & 0,19 \\
\hline $\begin{array}{l}\text { Pembayaran kartu kredit baik melalui } \\
\text { ATM, e-banking dan teller. }\end{array}$ & 0,97 \\
\hline $\begin{array}{l}\text { Pembelian pulsa telepon melalui e-banking } \\
\text { dan ATM }\end{array}$ & 4,28 \\
\hline $\begin{array}{l}\text { Pembelian pulsa listrik melalui e-banking } \\
\text { dan ATM }\end{array}$ & 0,58 \\
\hline $\begin{array}{l}\text { Pembayaran listrik pasca bayar melalui } e \text { - } \\
\text { banking, teller dan ATM }\end{array}$ & 1,46 \\
\hline $\begin{array}{l}\text { Pembayaran telepon pascabayar melalui } e \text { - } \\
\text { banking, teller dan ATM }\end{array}$ & 5,73 \\
\hline Pembayaran iuran sekolah & 0,10 \\
\hline Info saldo melalui ATM Bank lain & 3,11 \\
\hline Pembuatan referensi Bank & 0 \\
\hline Transaksi sistem kliring Indonesia & 0,58 \\
\hline Transaksi remittance dan inkaso & 0 \\
\hline $\begin{array}{l}\text { Transaksi di mesin electronic data capture } \\
\text { (EDC) }\end{array}$ & 8,94 \\
\hline Cetak rekening koran & 0,10 \\
\hline Pembayaran safe deposit box (SDB) & 0,1 \\
\hline Autodebet pembayaran telpon paska bayar & 3,40 \\
\hline Autodebet listrik paska bayar & 3,40 \\
\hline Pembayaran Indovision melalui ATM & 1,17 \\
\hline Saldo tidak mencukupi & 0,10 \\
\hline Total & 100 \\
\hline
\end{tabular}

Tabel 8. KMO dan Bartlett's Test

\begin{tabular}{llc}
\hline Keiser-Meyer-Olkin Measure & 0,501 \\
\hline $\begin{array}{l}\text { Barlett's Test of } \\
\text { Sphericity }\end{array}$ & $\begin{array}{l}\text { Approx. Chi } \\
\text { Square }\end{array}$ & 41.419 \\
& Df & 3 \\
& Sig. Bartlett & 0,000 \\
\hline
\end{tabular}

Setelah mendapatkan faktor yang terbentuk melalui proses reduksi, maka perlu mencari persamaannya.

Tabel 9. Component score coefficient matrix

\begin{tabular}{ll}
\hline & Component \\
& 1 \\
\hline $\mathrm{R}$ & .277 \\
$\mathrm{~F}$ & .886 \\
$\mathrm{M}$ & .863 \\
\hline
\end{tabular}

Extraction Method: Principal Component Analysis
Menggunakan hasil Tabel 8, maka persamaan yang terbentuk adalah:

$$
\mathrm{F} 1=0,277 \mathrm{R}+0,886 \mathrm{~F}+0,883 \mathrm{M}
$$

Skor yang diperoleh tersebut kemudian digunakan sebagai faktor pengali dalam poin pembobotan (weighted points) peubah RFM. Peubah Recency (R) dengan faktor pengali adalah satu (1), peubah Frequency (F) faktor pengali adalah tiga (3) dan peubah Monetary (M) faktor pengali adalah tiga (3). Setelah weighted points diperoleh, kemudian dilakukan perhitungan cummulative points untuk setiap nasabah dengan menjumlah-kan weighted points dari setiap peubah $\mathrm{R}, \mathrm{F}$ dan $\mathrm{M}$. Nilai RFM kemudian diperoleh dari penjumlahan weighted points ketiga peubah.

Berdasarkan skor RFM secara keseluruhan, dilakukan segmentasi sesuai skor tersebut dibagi menjadi lima segmen yang terbagi menjadi segmen Black, Blue, Silver, Emas dan Platinum. Hal tersebut tertuang pada Tabel 10.

Tabel 10. Segmentasi nasabah tabungan siaga kerjasama menurut nilai RFM

\begin{tabular}{lcl}
\hline \multicolumn{1}{c}{ Segmen } & $\begin{array}{r}\text { Nilai } \\
\text { RFM }\end{array}$ & \multicolumn{1}{c}{ Matrik RFM } \\
\hline 1= Black & $5-15$ & R rendah, F rendah, M rendah \\
2= Blue & $16-25$ & R rendah, F tinggi, M tinggi \\
3= Silver & $26-35$ & R tinggi, F rendah, M tinggi \\
4= Emas & $36-45$ & R tinggi, F tinggi, M rendah \\
5= Platinum & $46-55$ & R tinggi, F tinggi, M tinggi \\
\hline
\end{tabular}

Mayoritas nasabah Tabungan SiAga kerjasama XYZ Cabang Bogor terdapat pada segmen 3 (57\%), yang dapat dilihat pada Gambar 1 . Kemudian diikuti dengan nasabah segmen 4 (23\%) dan segmen $5(12 \%)$, sedangkan jumlah paling sedikit, yaitu nasabah pada segmen 2 (3\%). Apabila digabung antara segmen 3, 4 dan 5, maka jumlahnya 92 persen, hal tersebut menunjukkan bahwa nasabah Tabungan SiAga Kerjasama XYZ cukup loyal (Gambar 1).

Berdasarkan hasil penelitian, seluruh nasabah segmen Black mempunyai RFM yang rendah. Sementara pada segmen Blue, hanya 33\% nasabah dengan tingkat recency tinggi, 67\% memiliki tingkat recency rendah. Pada aspek frequency, keseluruhan nasabah segmen Blue memiliki tingkat frequency rendah. Sedangkan pada aspek monetary, segmen Blue cenderung memiliki monetary yang tinggi (67\%), sementara sisanya (33\%) dengan tingkat monetary rendah. Sementara untuk segmen Silver, 98,2\% nasabah dengan tingkat recency tinggi, 1,8\% dengan tingkat recency rendah. Sementara pada aspek frequency 
dan monetary, segmen Silver cenderung rendah $(80,4 \%)$ dengan tingkat frequency rendah $(89,3 \%)$ dengan tingkat monetary rendah. Hanya 19,6\% pada segmen silver dengan tingkat frequency tinggi dan 10,7\% dengan tingkat monetary tinggi. Sementara pada segmen Emas, baik dari segi recency dan frequency cenderung tinggi. Seluruh nasabah segmen Emas 100\% dengan tingkat recency tinggi, 95,7\% nasabah dengan tingkat frequency tinggi akan tetapi tingkat monetary rendah. Begitupun dengan segmen Platinum, keseluruhan nasabah $(100 \%)$ mempunyai tingkat RFM tinggi (Tabel 11). Oleh karena itu dapat disimpulkan bahwa semakin baik segmen tersebut semakin tinggi nilai RFM-nya.



Gambar 1. Persentase jumlah nasabah tabungan siaga kerjasama menurut segmentasi RFM di Bank XYZ Cabang Bogor
Tabel 11. RFM berdasarkan segmentasi.

\begin{tabular}{ccccc}
\hline Tingkat & \multicolumn{2}{c}{ R rendah } & \multicolumn{2}{c}{ R tinggi } \\
\cline { 2 - 5 } RFM & M rendah & M Tinggi & M rendah & M Tinggi \\
\hline F rendah & Black & Blue & Silver & \\
F tinggi & & & Emas & Platinum \\
\hline
\end{tabular}

\section{Analisis Korespondensi Antara Segmen dan Pofil Sosial Nasabah}

Analisis korespondensi bertujuan untuk mengetahui kemiripan dan keterkaitan (Greenacre, 2007) antara segmen dengan profil sosial nasabah. Gambar 2 menunjukkan nasabah pada segmen Silver dan segmen Platinum mempunyai profil wilayah, pendidikan, pendapatan dan usia yang relatif mirip. Segmen Silver dan Platinum didominasi oleh nasabah wilayah kabupaten Bogor dan Bogor Utara.

Segmen Silver dan Platinum didominasi oleh nasabah dengan pendapatan Rp1-5 juta, Rp25-50 juta dan Rp50-100 juta. Pendidikan SMP berdekatan dengan segmen Silver. Kelompok usia 50-60 tahun berdekatan dengan segmen Silver dan Platinum, sehingga mendominasi segmen Silver dan Platinum.

Gambar 2 menunjukkan bahwa segmen Blue berdekatan dengan wilayah Bogor Barat, Bogor Selatan dan Depok. Kelompok segmen Blue dan Emas memiliki kemiripan profil dari segi pendidikan dan pendapatan yang saling berde-

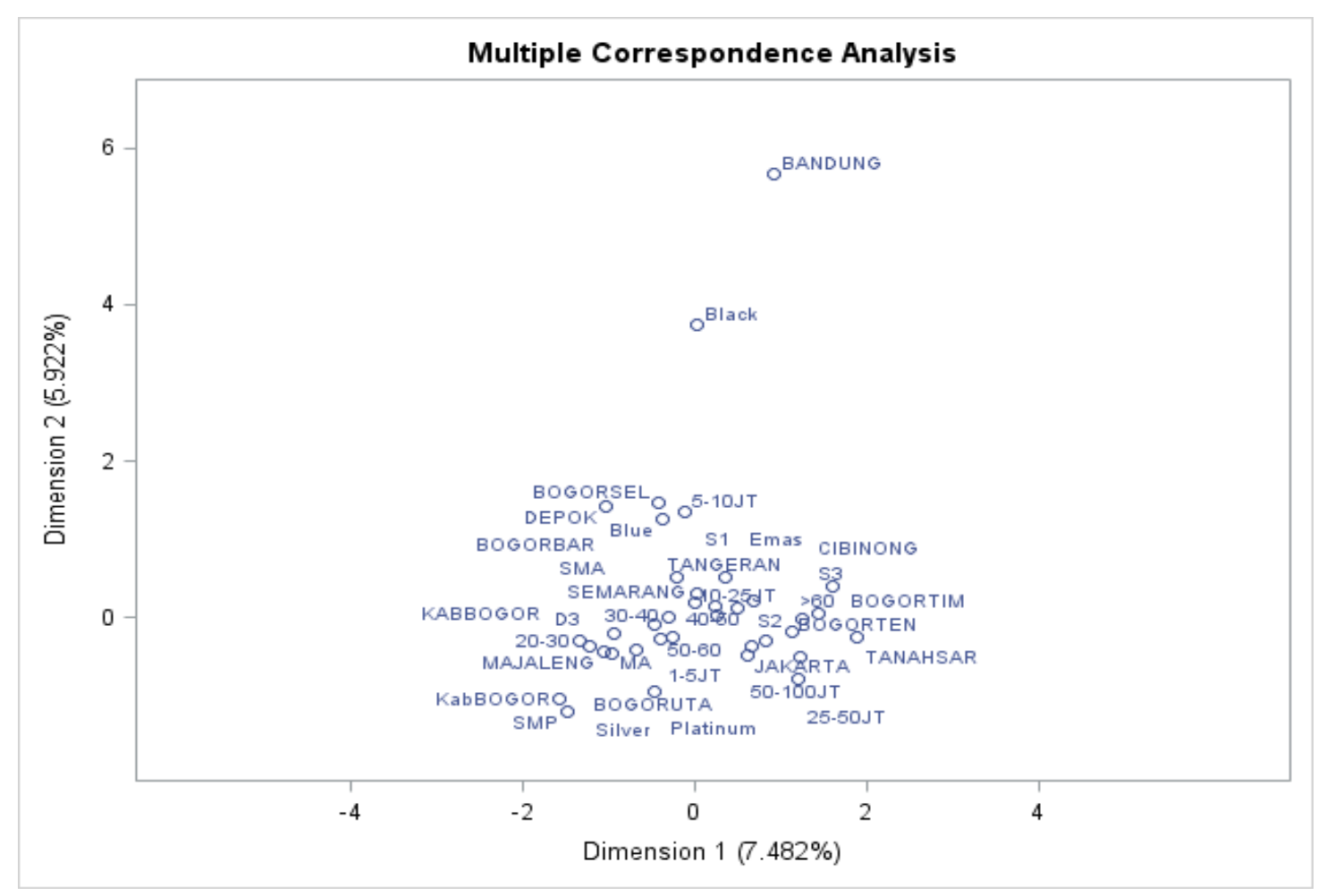

Gambar 2. Korespondensi antara segmen dengan profil sosial nasabah 
katan, yaitu pendidikan S1 dan pendapatan Rp510 juta. Segmen Emas didominasi dengan nasabah wilayah Cibinong dan Tangerang, serta pendidikan, yaitu kelompok S1 dan kelompok S3, sedangkan segmen Black berdekatan dengan kelompok wilayah Bandung. Dua dimensi plot korespondensi segmen dan profil sosial nasabah dapat menjelaskan $5,92 \%+7,48 \%=13,40 \%$ keragaman.

\section{Analisis Relationship melalui Persepsi Nasabah terhadap CRM}

Bedasarkan hasil penelitian, persepsi nasabah paling tinggi adalah kesesuaian database yang dimiliki Bank XYZ. Selain itu, pada umumnya nasabah menyatakan setuju bahwa antusiasme, keramahan, kesopanan dan pengetahuan yang dimiliki pihak perbankan baik. Selain itu, nasabah setuju bahwa pihak perbankan mengenal baik nasabah dan telah memiliki catatan mengenai profil nasabah.

Persepsi nasabah sangat rendah atau menyatakan tidak setuju mengenai pemberian souvenir yang dilakukan oleh Bank XYZ, baik pada hari raya, hari ulang tahun maupun diluar hari spesial. Komunikasi yang dilakukan pihak bank XYZ melalui media komunikasi telepon tidak secara berkala atau lebih dari sebulan sekali, bahkan hampir tidak pernah. Persepsi nasabah mengenai tindakan penanganan pada keluhan pelanggan, pertanyaan dan tindakan pada setiap keluhan pada umumnya dinilai baik, namun sebagian nasabah lagi menyatakan netral. Selain itu, persepsi nasabah mengenai pemenuhan kebutuhan pelanggan seperti program khusus yang sesuai dengan keinginan nasabah, kemudahan dalam transaksi, inisiatif peningkatan pelayanan yang sudah berjalan, pemenuhan kebutuhan dan keinginan nasabah, respon yang tepat pada kebutuhan nasabah, pemenuhan kebutuhan nasabah secara konsisten dan dalam, pemberian pelayanan dengan cepat dan tepat, menomorsatukan kepentingan nasabah dan penciptaan kepercayaan terhadap nasabah dinilai cukup baik. Sebagian kecil menyatakan netral dan tidak setuju. Nasabah menilai bahwa Bank XYZ belum memanfaatkan dengan optimal mengenai penggunaan teknologi seperti email, short message service (SMS) dalam berkomunikasi dengan nasabah. Selain itu, persepsi nasabah mengenai kemudahan transaksi dengan teknologi yang diberikan Bank XYZ seperti internet banking dan sms banking belum cukup familiar atau nasabah tidak setuju karena ketakutan dalam kemudahan terjadinya pembobolan dana melalui jaringan teknologi seperti internet banking maupun sms banking.

Bedasarkan penelitian, persepsi nasabah mengenai aspek people yang terdiri dari antusiasme, keramahan dan kemampuan merupakan aspek yang dinilai baik. Sementara itu, pada aspek proses hanya identifikasi profil yang dinilai cukup baik oleh nasabah pada umumnya. Untuk peubah komunikasi, pemberian souvenir pelanggan, pemenuhan kebutuhan pelanggan, nasabah menilai masih belum cukup puas.

Persepsi nasabah mengenai aspek teknologi yang digunakan Bank XYZ untuk media komunikasi baik melalui sms, email, maupun telepon, nasabah menyatakan bahwa Bank XYZ jarang melakukannya atau hampir tidak pernah. Begitu pula dengan teknologi transaksi seperti $e$ banking (internet banking dan sms banking), sebagian besar nasabah belum memanfaatkannya karena dalam pemikiran nasabah masih belum percaya mengenai tingkat keamanan e-banking. Sedangkan untuk kelengkapan database, semua nasabah menyatakan setuju bahwa database yang dimiliki Bank XYZ sesuai dengan data pelanggan sebenarnya pada saat melakukan registrasi.

\section{Analisis Hubungan CRM dan Loyalitas}

Berdasarkan hasil penelitian yang menggunakan analisis regresi diperlihatkan bahwa peubah people, proses dan teknologi terhadap total skor recency menghasilkan p-value yang lebih besar dari alpha $5 \%$, artinya tidak tolak $\mathrm{H} 0$ atau peubah people, proses dan teknologi tidak memiliki pengaruh terhadap nilai skor recency. Artinya bahwa pihak perbankan baik dari segi people, proses dan teknologi tidak memengaruhi waktu transaksi terakhir nasabah mengunjungi Bank XYZ.

Sementara hasil regresi peubah people, proses dan teknologi terhadap nilai frekuensi menghasilkan $p$-value untuk peubah proses $=0.013$ lebih rendah dari alpha 5\%, artinya persepsi nasabah mengenai proses berpengaruh terhadap frekuensi nasabah. Sementara untuk people dan teknologi tidak memengaruhi frekuensi nasabah mengunjungi atau bertransaksi di Bank XYZ.

Hal tersebut sama seperti analisis regresi peubah people, proses dan teknologi terhadap nilai monetary menghasilkan p-value untuk peubah proses $=0.002$ lebih rendah dari alpha $5 \%$, artinya persepsi nasabah mengenai proses berpengaruh 
terhadap monetary nasabah, pengaruh proses terhadap monetary adalah positif. Selain itu, jika menggunakan alpha $10 \%$ dapat dilihat juga $p$ value teknologi nyata pada $p$-value $=0.082$ (lebih kecil dari alpha) artinya dengan selang kepercayaan $90 \%$ persepsi teknologi nyata berpengaruh terhadap monetary nasabah dengan pengaruh positif. Berdasarkan hasil tersebut, aspek proses bisnis paling memengaruhi frekuensi dan monetary nasabah dalam bertransaksi, kemudian diikuti dengan aspek teknologi yang mempengaruhi monetary nasabah dalam mengeluarkan dana untuk setiap kali bertransaksi di Bank XYZ. Sedangkan aspek people tidak memengaruhi tinggi atau rendahnya nilai RFM yang dilakukan oleh nasabah.

Jelas terlihat bahwa segmentasi nasabah Platinum memiliki rataan nilai persepsi paling tinggi pada people kemudian proses dan teknologi. Selain itu dapat dilihat pula untuk nasabah dengan segmentasi Platinum selalu memiliki rataan nilai persepsi lebih tinggi dari segmentasi lain. Nilai persepsi pada people dan proses bisnis tertinggi setelah Platinum adalah segmen Emas, diikuti dengan segmen Blue, kemudian segmen Silver dan terakhir segmen Black. Untuk aspek teknologi, persepsi yang terbaik dinyatakan oleh Platinum, kemudian Blue, Emas, Silver dan terakhir tetap pada segmen Black. Hal tersebut dapat dilihat jelas pada Tabel 12.

Uji khi kuadrat menunjukkan p-value 0.01 lebih kecil dari alpha 5\%, maka tolak H0 artinya pada tingkat kepercayaan 95\% terdapat hubungan persepsi nasabah dengan segmentasi. Hasil ini menunjukkan semakin tinggi nilai RFM (nasabah loyal), maka semakin tinggi persepsi setuju bahwa pihak perbankan baik dalam melayani, menangani serta melakukan hubungan yang baik dengan nasabah, baik dari aspek people, process maupun technology.

\section{Implikasi Kajian}

Segmen Black mempunyai nilai RFM rendah dikarenakan tidak aktif dan jauh dari outlet Bank XYZ, sehingga nasabah jarang/hampir tidak pernah melakukan transaksi di outlet Bank XYZ Cabang Bogor. Dari segi pendapatan, nasabah ini cukup besar, sehingga nasabah segmen ini perlu dirangsang untuk melakukan transaksi secara rutin dari waktu ke waktu. Bank XYZ dapat menyediakan pelayanan yang sesuai dengan kebutuhan nasabah dan secara periodik menghubungi nasabah melalui telesales dan memberikan reward untuk merangsang peningkatan transaksi dan kunjungan ke Bank XYZ. Selain itu, pihak perbankan memberikan pengetahuan kepada nasabah mengenai penggunaan e-banking atau ATM, sehingga lebih efisien dalam waktu, tempat dan biaya.

Segmen Blue merupakan nasabah dengan pola $\mathrm{R}$ rendah, $\mathrm{F}$ rendah dan $\mathrm{M}$ tinggi. Nasabah segmen ini menguntungkan Bank XYZ namun tergolong tidak aktif (dorman). Nasabah mempunyai dana lebih, namun tidak aktif atau tidak cukup waktu mengunjungi Bank. Nasabah pada segmen ini perlu diperlakukan secara khusus untuk melakukan transaksi lebih banyak. Strategi

Tabel 12. Deskriptif statistik: people, process dan teknologi

\begin{tabular}{rrrrrrrrr}
\hline Peubah & segmen & \multicolumn{1}{c}{$\mathrm{N}^{*}$} & \multicolumn{1}{c}{ Mean } & SE Mean & St Deviasi & Minimum & \multicolumn{1}{c}{ Q1 } & Median \\
\hline People & 1 & 5 & 0,6800 & 0,0490 & 0,1095 & 0,6000 & 0,6000 & 0,6000 \\
& 2 & 3 & 0,79259 & 0,00741 & 0,01283 & 0,7778 & 0,7778 & 0,8000 \\
& 3 & 57 & 0,7330 & 0,0135 & 0,1022 & 0,6000 & 0,6000 & 0,8000 \\
& 4 & 23 & 0,8058 & 0,0155 & 0,0744 & 0,6000 & 0,8000 & 0,8000 \\
\hline Process & 5 & 12 & 0,8315 & 0,0288 & 0,0790 & 0,7778 & 0,8000 & 0,8000 \\
\hline & 1 & 5 & 0,5513 & 0,0184 & 0,0412 & 0,5200 & 0,5200 & 0,5236 \\
& 2 & 3 & 0,7067 & 0,0581 & 0,1007 & 0,6000 & 0,6000 & 0,7200 \\
& 3 & 57 & 0,6249 & 0,0123 & 0,0925 & 0,4800 & 0,5236 & 0,6000 \\
& 4 & 23 & 0,7099 & 0,0134 & 0,0641 & 0,5236 & 0,6800 & 0,7200 \\
& 5 & 12 & 0,7609 & 0,0198 & 0,0687 & 0,6000 & 0,7200 & 0,7891 \\
\hline & 1 & 5 & 0,6400 & 0.0187 & 0,0418 & 0,6000 & 0,6000 & 0,6500 \\
& 2 & 3 & 0,7333 & 0.0667 & 0,1155 & 0,6000 & 0,6000 & 0,8000 \\
& 3 & 57 & 0,68947 & 0.00999 & 0,07544 & 0,60000 & 0,62500 & 0,70000 \\
& 4 & 23 & 0,7022 & 0.0149 & 0,0715 & 0,6000 & 0,6000 & 0,7000 \\
& 5 & 12 & 0,7583 & 0.0193 & 0,0699 & 0,6000 & 0,7000 & 0,8000 \\
\hline
\end{tabular}


yang dapat dilakukan yaitu memberikan hadiah, souvenir atau cashback bagi nasabah yang melakukan transaksi, sehingga nasabah lebih tertarik dalam meningkatkan transaksi perbankan. Selain itu, up-selling cocok untuk nasabah segmen ini.

Nasabah dengan pola $\mathrm{R}$ tinggi, $\mathrm{F}$ rendah dan $M$ rendah (segmen Silver) atau $R$ tinggi, $F$ tinggi dan $M$ rendah (segmen Emas) merupakan nasabah yang kurang memberikan keuntungan bagi Bank XYZ (monetary rendah). Terhadap nasabah dalam kelompok tersebut, Bank XYZ perlu melakukan pelayanan ekstra agar tertarik melakukan transaksi yang memberikan keuntungan bagi Bank XYZ. Strategi cross-selling merupakan strategi yang cocok untuk nasabah pada segmen ini. Strategi cross-selling yang dapat dilakukan yaitu promosi mengenai fitur-fitur yang belum dimanfaatkan oleh nasabah dan memberikan keuntungan tambahan bagi Bank XYZ. Contoh strategi cross-selling yaitu nasabah diberikan penawaran atau promosi produk lain seperti kartu kredit, Kredit Pemilikan Rumah (KPR), Kredit Serbaguna (KSG), ataupun promosi program-program berhadiah seperti pembe-rian poin pada setiap nasabah yang melakukan transaksi di Bank XYZ melalui ATM maupun ebanking.

Pada segmen Platinum, nasabah merupakan nasabah loyal denga nilai RFM tinggi. Persepsi nasabah Platinum mengenai pelayanan Bank XYZ sangat baik. Strategi yang perlu dilakukan agar nasabah tetap loyal yaitu memberikan pelayanan yang lebih dengan memberikan layanan prioritas, up-selling dan cross-selling untuk meningkatkan transaksi dan meminta refferal nasabah baru.

Aspek teknologi mempengaruhi ting-kat monetary nasabah, persepsi nasabah mengenai kesesuaian database sangat baik. Namun, nasabah belum memanfaatkan fasilitas teknologi dengan baik. Mengenai database nasabah agar selalu diupdate seminggu sekali. Selain itu, membuat laporan untuk mengontrol nasabah mana yang sudah memberikan nilai kontribusi dan belum memberikan kontribusi bagi bank XYZ. Memberikan transfer knowledge kemudahan serta kenyamanan dalam penggunaan teknologi perbankan kepada nasabah agar lebih efisien dalam waktu dan tempat.

Aspek people antusiasme, keramahan dan kemampuan dinilai baik, namun tidak memengaruhi nilai RFM nasabah. Oleh karena itu, perlu ditingkatkan dalam pelayanan yang sesuai dengan standar operasional perusahaan (SOP) yang mengacu pada MRI (Market Research Indonesia) dan memberikan inovasi-inovasi pelayanan terbaru dengan melakukan roleplay seminggu sekali untuk menambah pengetahuan customer service dan marketing mengenai produk maupun pemberian solusi, sehingga nasabah dapat meningkatkan transaksi di Bank XYZ.

Aspek proses bisnis mempengaruhi frekuensi dan monetary nasabah. Pada aspek proses, hanya identifikasi profil dinilai baik, sementara komunikasi, pemberian souvenir, pemenuhan kebutuhan pelanggan serta penanganan keluhan pelanggan dinyatakan kurang memenuhi harapan nasabah. Oleh karena itu, perlu ditingkatkan kembali komunikasi dengan pelanggan minimal sebulan sekali. Perhatian lebih mengenai pemberian souvenir dengan nasabah guna meningkatkan dana dan pemberian refferal nasabah baru. Memberikan program sesuai dengan kebutuhan nasabah, sehingga melakukan survey terlebih dahulu terhadap kebutuhan pelanggan yang disesuaikan dengan minat nasabah. Menampung keluhan pelanggan dengan baik, memberikan solusi secara cepat, tepat dan handal.

\section{KESIMPULAN}

Pemetaan segmentasi nasabah tabungan SiAga kerjasama XYZ berdasarkan tingkat loyalitas diukur dengan RFM atas lima segmen, dimana mayoritas nasabah terdapat pada segmen Silver, kemudian diikuti dengan nasabah segmen Emas, segmen Platinum, segmen Black dan paling sedikit yaitu segmen Blue.

Gabungan segmen Silver, Emas dan Platinum diperoleh 92\%. Hal tersebut mengindikasikan nasabah tabungan SiAga Kerjasama Bank XYZ cukup loyal. Dalam hal ini, kelompok usia, pendidikan, pendapatan dan wilayah tidak terdapat hubungan antara segmen dengan profil sosial ekonomi nasabah. Disisi lain, segmen silver mendominasi semua kelompok.

Analisis relationship melalui persepsi nasabah terhadap CRM di Bank XYZ, didasarkan nilai persepsi paling tinggi (kesesuaian database yang dimiliki Bank XYZ). Namun, nasabah belum memanfaatkan fasilitas penggunaan teknologi dan belum merasakan mengenai kemudahan transaksi dengan teknologi yang diberikan Bank XYZ. Mengenai aspek people yang terdiri dari antusiasme, keramahan dan kemampuan merupakan aspek yang dinilai baik. Sementara 
itu, untuk aspek proses hanya identifikasi profil yang dinilai cukup baik oleh nasabah pada umumnya, sedangkan peubah komunikasi, pemberian souvenir pelanggan, pemenuhan kebutuhan pelanggan, nasabah menilai masih belum cukup puas, untuk penanganan keluhan nasabah berpendapat netral karena belum pernah mengeluh.

Analisis hubungan CRM dengan loyalitas, menghasilkan aspek proses bisnis yang dipengaruhi frekuensi dan monetary nasabah dalam bertransaksi, kemudian diikuti dengan aspek teknologi yang memengaruhi monetary nasabah untuk mengeluarkan dana setiap kali bertransaksi di Bank XYZ. Untuk aspek people tidak memengaruhi tinggi atau rendahnya nilai RFM yang dilakukan oleh nasabah, dimana aspek people, proses dan teknologi tidak memengaruhi recency atau kunjungan terakhir nasabah ke Bank.

\section{DAFTAR PUSTAKA}

Andreani, F, Yesslyn Sumargo dan Chen Lie. 2012. The Influence of Customer Relation-ship Management (CRM) on Customer Loyalty in JW Marriot Hotel Surabaya. Jurnal Manajemen dan Kewirausahaan, 14(2): 156163.

Ariana, AAGB. 2011. Customer Segmentation dengan Metode Self Organizing Map (studi Kasus U.D Fenny). Jurnal Lontar Komputer, 2(1): $1-7$.

Aviliani, U. Sumarwan, I. Sugema, A. Saefuddin. 2011. Segmentasi Nasabah Tabungan Mikro Berdasarkan Recency, Frequency dan Monetary Kasus Bank BRI. Jurnal Keuangan dan Perbankan, 13(1): 95-109.

Bacila MF, Adrian R dan Ioan LM. 2012. RFM Based Segmentation: An Analysis of a Telecom Company's Customers. Journal International Conference "Marketing - from Information to Decision". 5th Ed: 52-62.

Baroroh, Ali. 2013. Analisis Multivariat dan Time Series dengan spss 21. PT Elex Media Komputindo Gramedia, Jakarta.

Bukopin. 2012. Mengukir Prestasi Membentuk Perspektif Bank Bukopin Laporan Tahunan 2012. Bank Bukopin, Jakarta.

Goldenbery, B. 2002. Successful CRM : Getting the People, Process and Technology. Prentice Hall, New Jersey.
Greenacre, Michael. 2007. Correspondence Analysis in Practice. Chapman \& Hall/CRC, Newyork.

Hussain, Iftikhar, Mazhar Hussain, Shahid Hussain and MA. Sajid. 2009. Customer Relationship Management: Strategies and Practices Inselected Banks of Pakistan. International Review of Business Research Papers 5(2): 117-132.

Imasari, Kartika dan Kezia K Nursalin. 2011. Pengaruh Customer Relationship Management Terhadap Loyalitas Pelanggan pada PT BCA, tbk. Jurnal Fokus Ekonomi (FE), 10(3): 183-192.

Iriana, Reiny dan Francis B. 2006. Customer Relationship Management (CRM) System Implementations [internet]. The International Journal of Knowledge, Culture and Change Management 6(2): 137-147. [diakses 2014 Maret 14].

Irmariani, Rida. 2013. Analisis Customer Relationship Management BPR Supra Bogor. Tugas Akhir [Tesis]. Magister Manajemen Bisnis, Sekolah Pascasarjana, Institut Pertanian Bogor.

Kalakota, Ravi dan Robinson Marcia. 2001. Ebusiness 2.0. Roadmap for Success. Boston.

Kanaidi dan A. Kurniawan. 2012. Analisis Customer Relationship Management (CRM) pada SBU Pos Admail. Jurnal Manajemen Pemasaran Politeknik Pos Indonesia. Jurnal Banking \& Management 1(1): 25-34.

Kotler P dan Keller KL. 2007. Manajemen Pemasaran (Terjemahan). PT Indeks. $12^{\text {th }}$ Ed Jilid 2, Jakarta (ID).

Miglautsch JR. 2000. Thoughts on RFM scoring. Journal of Database Marketing 8(1): 67-72.

Mishra, Alok dan D. Mishra. 2009. Customer Relationship Management: Implementation Process Perspective. Jurnal of Atilim University, Ankara, Turke: 83-99.

Munandar, D. 2006. Pengaruh customer Relationship Management Terhadap Loyalitas Pelanggan bIsnis PT Frisian Flag Indonesia Bandung. Majalah Ilmiah Unikom 7(1): 137147.

Nadlifatin, Reny, Mudjahidin, Mahendrawathi Rr. 2009. Pengukuran Performansi Praktik Pengelolaan Hubungan Pelanggan dengan Menggunakan Kerangka crm Scorecard (Studi Kasus: PT Bank Mandiri (Persero) tbk). [diakses di www.digilib.its.ac.id] 
Prihartono, A.G., U. Sumarwan, N.A. Achsani, Kirbrandoko. 2012. The Influence of Loyalty Index Score on Consumer Credit Profitability. Asia Pacific Journal of Finance and Banking Research 6( 6): 15-25.

Siahaan, H. 2008. Costumer Relationship Management (CRM) Sebagai Sarana Meraih Image Positif untuk Perpustakaan. Jurnal Studi Perpustakaan dan Informasi 4(2): 80-87.

Sumarwan, U. 2011b. Riset Pemasaran dan Konsumen. IPB Press, Bogor.
Vazifehdust, Hossein, Shahnavazi A, Jourshari MRT, Fataneh SS. 2012. Investigation Critical Success Factors of Customer Relationship Management Implementation. World Applied Sciences Journal 18(8): 1052-1064.

Winner, Russell S. 2001. A Framework for Customer Relationship Management. California Management Review Summer 43(4): 89-107.

Womack, D K dan Claudia G B. 2004. System and Method for Generating a Strategic Marketing Plan for Enhancing Customer Relations. Patent Application Publication USA: $1-6$. 